\title{
AN APPLICATION OF PHySics EXPERIMENTS OF High SCHOOL BY USING AUgMENTED REALITY
}

\author{
Hussain Mohammed Abu-Dalbouh, Samah Mohammed AlSulaim, Shaden \\ Abdulaziz AlDera, Shahd Ebrahim Alqaan, Leen Muteb Alharbi and Maha \\ Abdullah AlKeraida
}

Qassim University, Computer Science Department, College of Sciences and Arts in Unaizah, Qassim, Kingdom of Saudi Arabia

\begin{abstract}
There has been done little research to validate the utility and usability of virtual and augmented reality environments. The evaluation of usability of these new technologies is very important to design systems that are more intuitive than a traditional method. Such an evaluation is also important for future development of applications that can gain from this new technology. The augmented reality (AR) is a technology that embedded virtual object (video, picture and $3 D$ object) to the user view the real world. The combination of AR technology with the educational content creates new type of automated applications and acts to enhance the effectiveness and attractiveness of teaching and learning for students in real life scenarios. The study aims to improve the teaching methods used in secondary school by employing modern educational technology and thus assess the effectiveness of AR apps in teaching students the physics experiments. Therefore, in this study we took the challenge of adapting this technology to facilitate physics subject in secondary school.
\end{abstract}

\section{KEYWORDS}

Augmented Reality, Physics, Education, System, Students, Teachers, Technology, Mobile, Lab, Virtual Reality

\section{INTRODUCTION}

Inundating students to genuine world and cooperate them with that world generally cannot be helpful. In spite of the fact that the regular world is three- dimensional, we want to utilize twodimensional media in training which is exceptionally advantageous, natural, adaptable, versatile and economical. However, it is static and does not offer the dynamic substance. Then again computer produced three-dimensional virtual condition can be utilized yet these scenes requires elite computer illustrations which is more costly than others.

Even though bunches of chances virtual universes may display for educating and learning, it is difficult to give a sufficient dimension of authenticity. At the point when clients are totally submerged in this condition they wind up separated from the genuine condition. In this way, it gives you virtual things by displaying this present reality you are encountering. Successful and prosperous societies are one of the most powerful and dominant societies in this world. For a society to be strong and developed, it should be based on several elements, most notably science and education. Without knowing what human societies have developed, flourished and reached what it is today. But we as human may have difficulty in understanding some things, especially as students, we find difficult to understand a lot of things in our study, one of them is the scientific experiments in scientific material such as biology, physics and chemistry, especially physics the scope of this study. 
You may have difficult understand the experiments written in the book, and you may not have the ability to experience and see, and since we as a human, our eyes eager for visual information and the brain accepted it faster and more established than the written information.

Today has ever-expanding applications such as science, education, engineering, interactive, multimedia, medicine.ispivisualization through visual images is an effective way to deliver the idea in an easy simple way and more established in the brain.

Nowadays, visualization is a part of the education and people enjoy more with visual data. Richard Hamming said: "The purpose of computing is insight, not numbers". According to Charles and Chris (2005) the goal of visualization is leverage existing scientific methods by providing new scientific insight through visual methods. We will use a technology that will give the ability to see the physical experience at any time and any place with your own phone in a particular application.

Imagine a technology with which you could see more than others see, hear more than others here. It is a technology to perceive completely computational elements. It also objects within our realworld experience, entire creatures and structures even that helps us in our daily activities, with such technology:

- Mechanics could see instructions what to do next when repairing an unknown piece of Equipment.

- Surgeons could see ultrasound scans of organs while performing surgery on them.

- Fire fighters could see building layouts to avoid otherwise invisible hazards [1].

Therefore, what all the students need, is seeing the experiment done in front of them as a video or as a (3D) object, this will make the understanding of the hard physics experiments easier. This technology is called augmented reality (AR), which can be applied to computers, tablets, and smartphones. AR affords the ability to overlay images, text, video, and audio components onto existing images or space. Research on AR has also demonstrated its extreme usefulness for increasing the student motivation in the learning process [2-6].

AR has already begun to help students learn more efficiently as well as increase their knowledge retention [7]. However, before AR becomes mainstream in education, like desktops, laptops, tablets, and even cell phones have become, special consideration must be taken into account on the usability, cost, power usage, visual appearance and the like, in order for content AR simulations activities to become part of the regular academic curriculum [8]. This study aims to explain the augmented reality (AR) is given about this new artificial and augmented environment. It also to develop a mobile application system that recognizes the experience picture in the book and feedback with a video or a 3D object of the experience.

\section{Problem of The STUdy}

The learning procedure is as yet restricted to customary techniques and the instructor's watchfulness in the introduction of data. Current practices in instruction don't misuse the numerous sorts of present day ICT apparatuses, applications, and administrations, nor do they convey data to the understudy in a solid structure that is near the truth in which he/she lives.

Despite the fact that the instruction of students at this stage requires instructing techniques that attention on utilization of the faculties and incorporation in the learning procedure [9], the utilization of ICT devices, applications, and administrations at the school organize is low contrasted with customary strategies. This issue can be tended to through the presentation of AR innovation into the school understudy's instructing and learning condition and utilizing it properly, with the goal that the educating and learning forms end up fun and useful while additionally accomplishing their ideal objectives. 
Hence, it is important to move the customary arrangement for displaying data to an AR approach. This methodology is described by anticipation and fun, and it attempts to solidify the displayed data in the understudy's brain. AR innovation may give a chance to the understudy, as indicated by his/her capacities, to create mental and psychological abilities that are not empowered by customary strategies. In like manner, this examination looked to find out about the viability of AR applications for educating and learning the material science subject in optional school in the State of Saudi.

\section{OBJECTIVES OF THE STUDY}

In the current study, the researchers introduce a new teaching method presenting information using modern technology and to determine the extent to which the student interacts with AR software. The researchers aim to improve the teaching methods used in secondary school by employing modern educational technology and thus assess the effectiveness of AR apps in teaching students the physics experiments. Finally, the researchers offer proposals and recommendations based on the results regarding the use of AR apps for teaching and learning.

\section{LiTERATURE REVIEW}

Augmented reality (AR) is a live direct or indirect view of a physical, real-world environment whose elements are "augmented" by computer-generated or extracted real-world sensory input such as sound, video, graphics or GPS data. It is related to a more general concept called computer-mediated reality, in which a view of reality is modified (possibly even diminished rather than augmented) by a computer. Augmented reality enhances one's current perception of reality, whereas, in contrast, virtual reality replaces the real world with a simulated one [10]. With the help of advanced AR technology (e.g. adding computer vision and object recognition) the information about the surrounding real world of the user becomes interactive and digitally manipulable. Information about the environment and its objects is overlaid on the real world. This information can be virtual or real, e.g. seeing other real sensed or measured information such as electromagnetic radio waves overlaid in exact alignment with where they actually are in space $[11,12]$. Augmented reality brings out the components of the digital world into a person's perceived real world. One example is an AR Helmet for construction workers, which display information about the construction sites. The first functional AR systems that provided immersive mixed reality experiences for users were invented in the early 1990s, starting with the Virtual Fixtures system developed at the U.S. Air Force's Armstrong Labs in 1992.

\subsection{Application of Augmented Reality}

Augmented Reality enhances a user's perception of and interaction with the real world. The virtual objects display information that the user cannot directly detect with his own senses. The information conveyed by the virtual objects helps a user perform real-world tasks. AR is a specific example of what Fred Brooks called Intelligence Amplification (IA): using the computer as a tool to make a task easier for a human to perform [13]. SEEp:As computers increase in power and decrease in size, new mobile, wearable, and pervasive computing applications are rapidly becoming feasible, providing people access to online resources always and everywhere [14]. This new flexibility makes a possible new class of applications that exploit the person's surrounding context [15]. Augmented reality has already presented a particularly powerful user interface (UI) to context-aware computing environments. AR systems integrate virtual information into a person's physical environment so that he or she will perceive that information as existing in their surroundings [16]. Mobile augmented reality systems provide this service without constraining the individual's whereabouts to a specially equipped area [17]. Augmented reality has many applications. First used for military, industrial, and medical applications, by 2012 its use expanded into the entertainment and other commercial industries [18]. 


\subsubsection{Medical}

Medical augmented reality takes its main motivation from the need of visualizing medical data and the patient within the same physical space. This would require real-time in-situ visualization of co- registered heterogeneous data and was probably the goal of many medical augmented reality solutions proposed in the literature (Figure 1). In 1968, Sutherland [19]. Suggested a tracked head-mounted display as a novel human-computer interface enabling viewpointdependent visualization of virtual objects. It was only two decades later when Roberts et al. implemented the first medical augmented reality system [20].

\subsubsection{Education}

Augmented Reality innovation is certainly not another issue. It has been utilized in fields, for example, military; medication; building plan; automated; tele-robotic; assembling, upkeep and fix applications; customerstructure; mental medicines, and so forth [21]. Showing data by utilizing virtual things that the client can't straightforwardly identify with his very own faculties can empower an individual to interface with this present reality in courses at no other time conceivable. We can change the position, shape, as well as other graphical highlights of virtual items with cooperation procedures increased reality underpins. Utilizing our fingers or movements of handheld gadgets, for example, shake and tilt we have a capacity to control virtual items, and additionally to physical articles in reality.

New possibilities for teaching and learning provided by AR have been increasingly recognized by educational researchers. The coexistence of virtual objects and real environments allows learners to visualize complex spatial relationships and abstract concepts [22]. Experience phenomena that is not possible in the real world [23], interact with two and three-dimensional synthetic objects in the mixed reality [24], and develop important practices that cannot be developed and enacted in other technology- enhanced learning environments [25]. These educational benefits have made AR one of the key emerging technologies for education over the next five years [26].

Augmented Reality can be connected for learning, stimulation, or edutainment by improving a client's impression of and collaboration with this present reality. Client can move around the three-dimensional virtual picture and view it from any vantage point, much the same as a genuine article. The data passed on by the virtual articles enables clients to perform certifiable undertakings. Substantial Interface Metaphor is one of the critical method to enhance learning. This property empowers control of three- dimensional virtual items essentially by moving genuine cards without mouse or console.

Augmented Reality can likewise be utilized to improve shared assignments. It is conceivable to create inventive PC interfaces that consolidate virtual and genuine universes to improve eye to eye and remote coordinated effort. These enlarged reality applications are increasingly like common up close and personal cooperation than to screen based joint effort [27].

Web innovations and web are well known, as a handy circumstance individuals still incline toward perusing books as opposed to confronting screens and reading material are still generally utilized. Another intriguing utilization of this innovation is in increased reality course books. These books are printed typically however indicate a webcam the book brings perceptions and associations planned. This is conceivable by introducing exceptional programming on a computer, utilizing extraordinary versatile applications or a site. This innovation enables any current book to be produced into an increased reality version after distribution. Utilizing 3D articles and sees, random and inventive media, recreations with various kinds of associations is the most straightforward methods for interfacing the two disconnected universes. Using Augmented Reality in printed book pages, reading material will wound up powerful wellsprings of data. Along these lines individuals with no computer foundation can in any case have a rich intuitive ordeal. 


\subsubsection{Video Games}

The gaming industry embraced AR technology. A number of games were developed for prepared indoor environments, such as AR air hockey, Titans of Space, collaborative combat against virtual enemies, and AR- enhanced pool table games [28]. Augmented reality allowed video game players to experience digital gameplay in a real-world environment. Companies andplatforms like Niantic and LyteShot emerged as major augmented reality gaming creators. EyeToy, PlayStation Eye, Kinect, Nintendo 3DS, PlayStation Portable, PlayStation Vita and some mobile devices, are examples of (AR Games) that use cameras to augment computer graphics onto live footage. The majority of AR software uses special cards which are read by the device to pinpoint where the graphics will form [29].

\section{DESIGN AND DEVELOPMENT OF MYLAB}

[30-32] discussed the functionality of the mobile tracking on patient progress system by using use case diagram. [33 and 34] discussed (Mobile Tracking on Patient Progress System-UML example), the study was covering aspects of mobility at the various views and diagrams of UML. [35]Is describing the extensions made in each of the UML diagrams, to allow the explicit representation of the proposed system. Then, modifications to the UML. [36] Is describing the functionality of the Electronic Health Record system by using use case diagram.

The proposed application is designed and implemented to view the required experience as a video or $3 \mathrm{D}$ model by recognizing a specific paper from the book. Therefore, Figure 2 shows the interaction between the user and the system. When the user clicks on the application it will display the main page with three buttons (Scan, Guide and About us) and the user can select one of them. The Scan button will move him to a page on which he/she chooses a Physics course, after that he/she will choose the level.

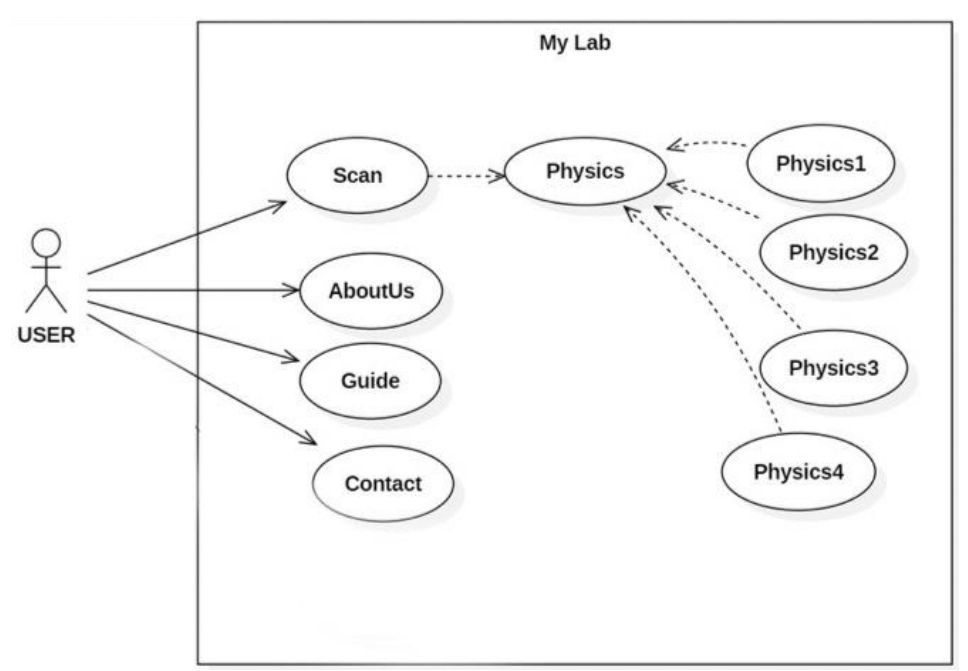

Figure 2.Use Case Diagram for Mylab application (Figure 1 shows that proposed Mylab application have many cases and some cases extended to other case) 
International Journal of Software Engineering \& Applications (IJSEA), Vol.11, No.1, January 2020

The following snapshots explain the Mylab application

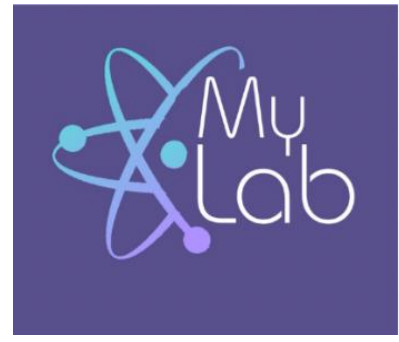

Figure 3. Application Logo

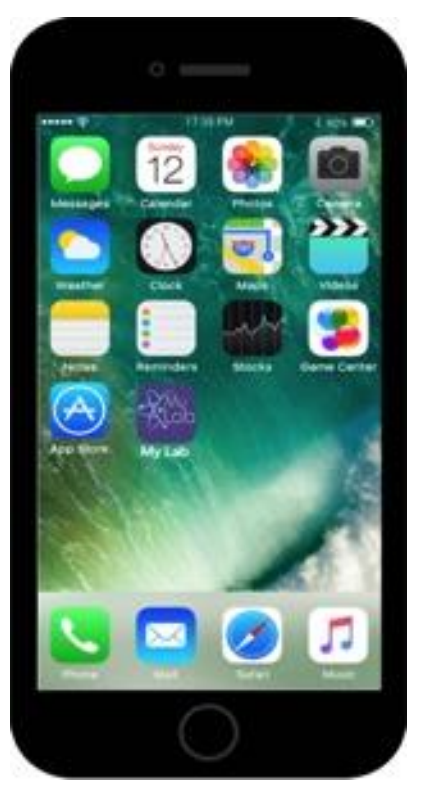

Figure 4. Application at Home Screen

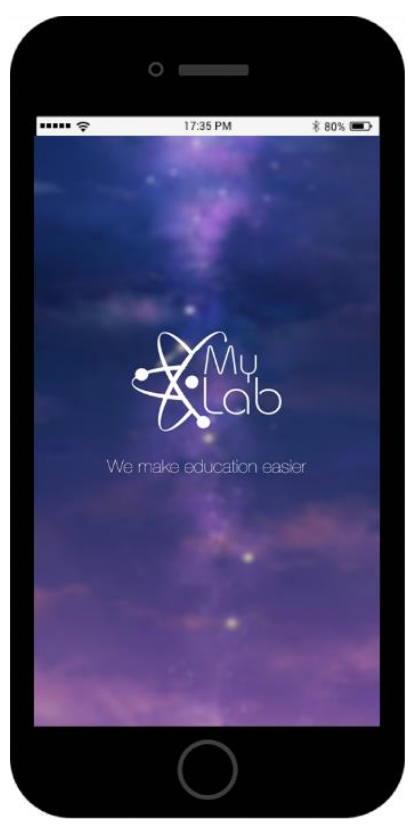

Figure 5. Main System Page (When user open (Mylab) application, will appear this screen then disappear automatically) 
International Journal of Software Engineering \& Applications (IJSEA), Vol.11, No.1, January 2020

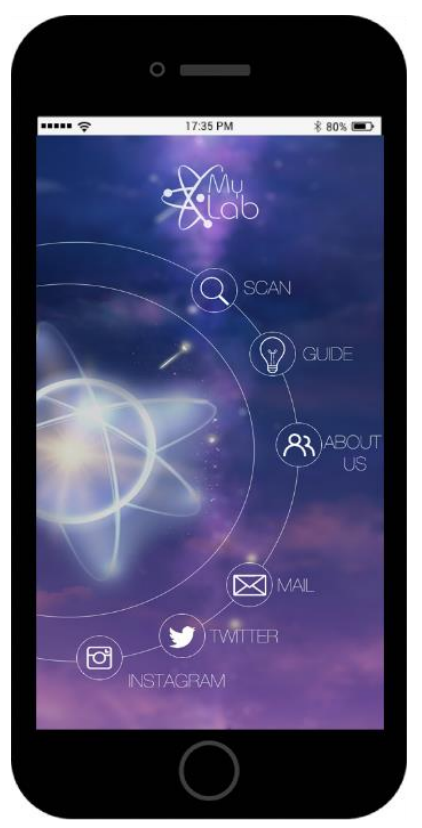

Figure 6. Mylab Buttons (User can choose over three screens, scan, guide and about us. 1. Scan: to start scan the book. 2. Guide: to know how to use this application and 3. About us contains some information about programmers.

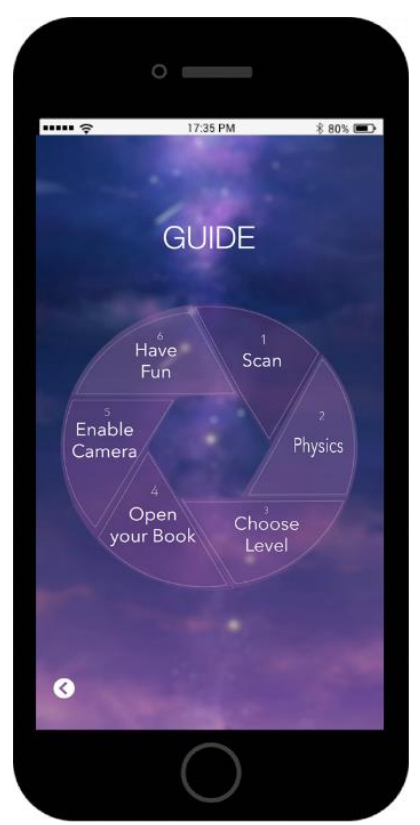

Figure 7. Guide Page (Guide page displays for user how to use (Mylab) application) 
International Journal of Software Engineering \& Applications (IJSEA), Vol.11, No.1, January 2020

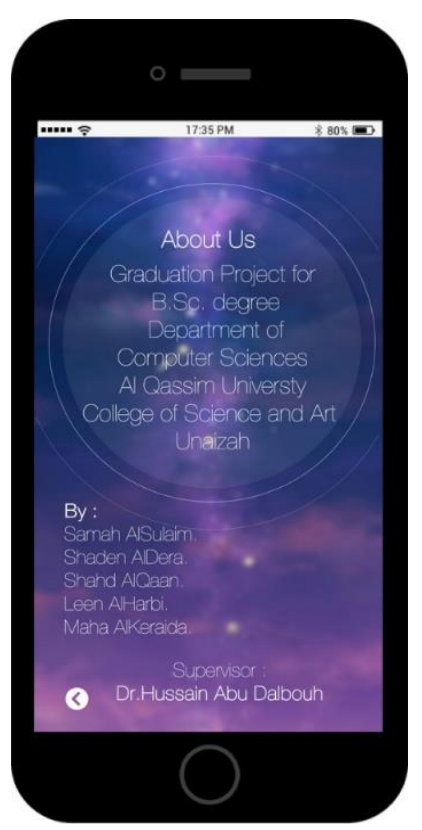

Figure 8. About us Page

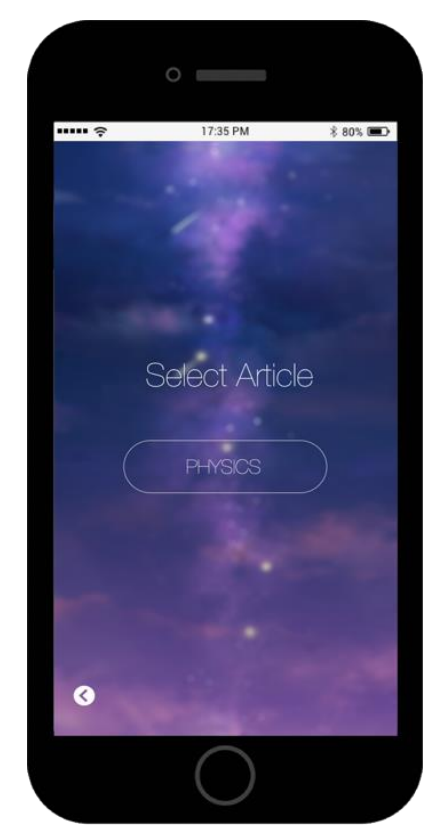

Figure 9. Course (When user clicks on (scan) will move to course, then user clicks on physics) 
International Journal of Software Engineering \& Applications (IJSEA), Vol.11, No.1, January 2020

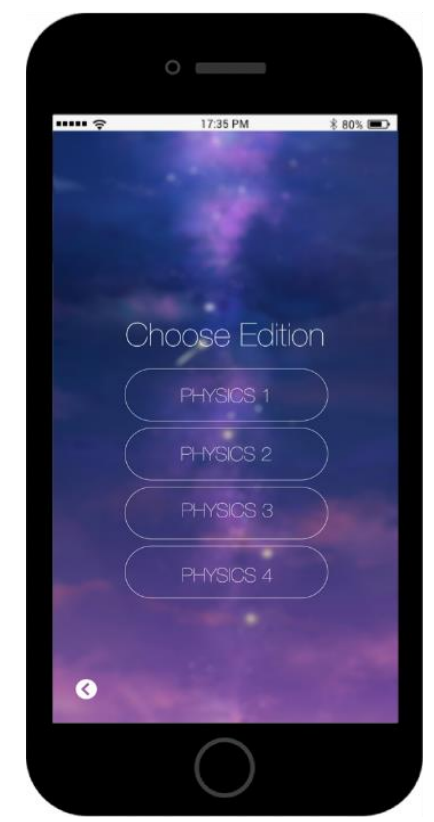

Figure 10. Physics Level (User clicks on his/her level)

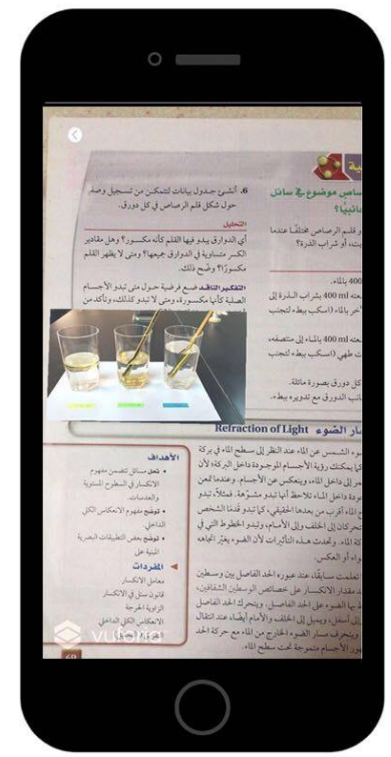

(A)

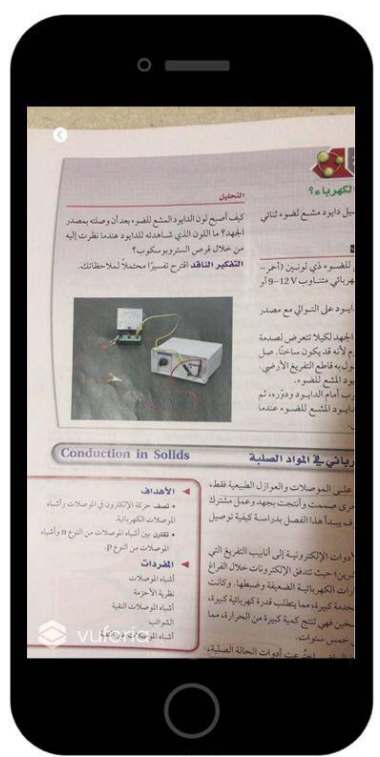

(B)

Figure 11.Scan Page (After user choose his level, will open camera to start scan by put device in front of page and interact with camera, the video will show if is exists (Figure $11 \mathrm{~A}$ ) and nothing will happen if not exist (figure $11 \mathrm{~B})$. If user clicks left arrow will move to previous screen)

\section{RESULT AND DISCUSSION}

Despite these positive AR content-creation experiences, an important question remains: Does AR technology increase learning? Building and using AR scenes combines active complex problem solving and teamwork to create engaging educational experiences to teach science, math or language skills, and studies have found that this activity enhances student motivation, involvement, and engagement. However, what is the real education benefit from using this 
technology in the classroom? Answering this question can be challenging because education quality stems from many factors, some of which are hard to quantify.

Most educational AR systems are single-use prototypes for specific projects, so it is difficult to generalize evaluation results. Overall, augmented books are promising educational tools, both in the laboratory and real classroom settings. They can enhance learning with print-only books or traditional interfaces by offering novel ways to experience educational content. The intuitive interaction possibilities and spatial visualization of 3D content that augmented physics experiments afford seem to be beneficial for learning. AR can also add more meaning to topics that students cannot possibly experience in the real world.

The results of our study show that AR seems to particularly benefit students who struggle in traditional text-based learning environments. Our results support earlier research that reveals the role of multimodality and interactivity in increasing engagement and immersion and in general learning support. Some researchers argue that interactivity can promote learning by activating certain cognitive processes. Interactivity can activate knowledge stored in long-term memory and cause the brain to integrate it with incoming information. Students who interact with the content can remember more than students who receive information only passively and better transfer what they have learned to new problems.

AR use in the classroom is still relatively new, but the technology's impact is increasing as AR platforms become more widely available. Current AR experiences have focused only on visually enhancing the real world, but they have established several key ideas about AR use in the classroom:

- AR technology is robust enough to deliver learning experiences, especially in augmented books and mobile AR applications;

- AR experiences should complement rather than replace traditional curriculum material;

- Valuable learning occurs during the development of AR content as well as in using the AR application itself; and

- AR provides real benefit for reading comprehension and in understanding spatial data, especially for those with low reading ability. As AR use broadens, however, the education model is likely to be quite different for students who have AR-ready mobile phones in their pockets and easy-to-use content tools at hand.

Therefore to evaluate the application according to its idea and the design of the screens, we distributed a questionnaire. Respondent consisted of 30, Physics Teachers and Students that were selected through convenience sampling. The aim of this evaluation is to discuss the results of the usability test conducted on the Mylab application. Usability test is one of the most fundamental methods in usability evaluation. The students and Physics Teachers have been asked to use the application for the purpose of testing. The respondents were asked to evaluate the prototype while doing the test tasks. Interviews and observations were used in order to gain more insight into the user's actions with the interface.

The findings of this research study are coherent and in compliance with the results of other studies, the finding show that the students by using the (Mylab) will Increased Motivation, Increased Attention, Increased Concentration and Increased Satisfaction. It is also, obvious that younger generation prefers technology intervened learning rather than conventional learning.

This is an auxiliary learning tool for upper secondary school students. The aim of this Mobile AR app for Physics experiment (Mylab) is to provide rigorous information beyond conventional experiment practices and additional learning materials. 


\section{ConClusion}

Professionals and researchers have striven to apply AR to classroom-based learning within subjects like chemistry, mathematics, biology, physics, astronomy, and to adopt it into augmented books and student guides. Estimated that AR has not been much adopted into academic settings due to little financial support from the government and lack of the awareness of needs for AR in academic settings. By augmenting the real world with virtual information, Augmented Reality (AR) provides new possibilities for education. AR is qualified to be utilized in instructive conditions and we distinguished numerous applications effectively applying AR to enhance learning: dialect training, preparing of mechanical aptitudes, and spatial capacities preparing. By and by, AR ought not be viewed as an enchantment slug in instructive conditions. Every AR application is in its own specific manner one of a kind and in this manner the recognized advantages may not have any significant bearing in every unique situation. Every application must be actualized completely to forestall downsides in client communication or framework disappointments so as to benefit from advantages. AR allows flexibility in use that is attractive AR technology can be utilized through a variety of mediums including desktops, mobile devices, and smart phones. The technology is portable and adaptable to a variety of scenarios. AR can be used to enhance content and instruction within the traditional classroom, supplement instruction in the special education classroom, extend content into the world outside the classroom, and be combined with other technologies to enrich their individual applications. The MyLab Application run on IOS systems allows the students of viewing the scientific experience at any time and in any place using the application, it support the education and make the studying more fun and easier for better understanding. This study presented the effects of AR use in physics experiments and training on student achievement and self-efficacy. As a result, it can be stated that the applications developed with AR technology can be used as effective tools in applied courses. Considering the results obtained in this study, following suggestions are offered to guide researchers and application developers in future AR studies:

It was concluded in the study that AR use increased student achievement. Based on this point, new studies can be planned in different fields and by using different sample levels.

Student' smart phones were used in this study. Although no problems were experienced in the use of these devices, due to their nature, they have limitations based on small screen sizes. Therefore, more appropriate devices for applications such as AR goggles can be used in future studies by receiving necessary support from related institutions.

The study was carried out with secondary School. Similar studies can be carried out with different sample groups in universities, institutions in which applied teaching is extensively used.

\section{REFERENCES}

[1] D.W.F. van Krevelen and R. Poelman, "A Survey of Augmented Reality Technologies, Applications and Limitations", 2010, http://kjcomps.6te.net/upload/paper1\%20.pdf

[2] Liu, T.-Y., \& Chu, Y.-L. (2010). Using ubiquitous games in an English listening and speaking course: Impact on learning outcomes and motivation. Computers \& Education, 55(2), 630-643. doi:10.1016/j.compedu.2010.02.023

[3] Jara, C. a., Candelas, F. a., Puente, S. T., \& Torres, F. (2011). Hands-on experiences of undergraduate students in Automatics and Robotics using a virtual and remote laboratory. Computers \& Education, 57(4), 2451-2461. doi:10.1016/j.compedu.2011.07.003 
[4] Bujak, K. R., Radu, I., Catrambone, R., MacIntyre, B., Zheng, R., \&Golubski, G. (2013). A psychological perspective on augmented reality in the mathematics classroom. Computers \& Education, 68, 536-544. doi:10.1016/j.compedu.2013.02.017

[5] Di Serio, Á., Ibáñez, M. B., \&Kloos, C. D. (2013). Impact of an augmented reality system on students' motivation for a visual art course. Computers \& Education, 68, 586-596. doi:10.1016/j.compedu.2012.03.002

[6] H.-Y. Chang, H.-K. Wu, and Y.-S. Hsu, "Integrating a mobile augmented reality activity to contextualize student learning of a socioscientific issue,", British Journal of Educational Technology, vol. 44, no. 3, pp. E95-E99, 2013.

[7] Billinghurst, M., \&Dunser, A. (2012). Augmented reality in the classroom. Computer, 45(7), 56-63

[8] D.W.F. van Krevelen and R. Poelman, "A Survey of Augmented Reality Technologies, Applications and Limitations", 2010, http://kjcomps.6te.net/upload/paper1\%20.pdf

[9] Wardle, F. (2000). How children learn: The order in mess. Children and Families, 14(4), 82-83.

[10] SteuerJonatha, "Defining Virtual Reality: Dimensions Determining Telepresence Archived", 2016 https://en.bywiki.com/wiki/Augmented_reality

[11] Chen, Brian X, "If You're Not Seeing Data, You're Not Seeing", 25 August 2009, https://www.wired.com/2009/08/augmented-reality/

[12] Rosenberg, L.B."The Use of Virtual Fixtures As Perceptual Overlays to Enhance Operator Performance in Remote Environments.", 1992https://en.bywiki.com/wiki/Augmented_reality\#Visual_art

[13] F. P. Brooks Jr, "The computer scientist as toolsmith ii", Communications of the ACM, vol. 39, no. 3, pp. 61-68, 1996.

[14] Shatte, J. Holdsworth, and I. Lee, "Mobile augmented reality-based context-aware library management system", Expert System with Application, vol 41, no. 5, pp. 2174-2185,2014.

[15] S. M. Land and H. T. Zimmerman, "Synthesizing perspectives on augmented reality and mobile learning," TechTrends, vol. 58, no. 1, p. 3, 2014.

[16] H.-Y. Chang, H.-K. Wu, and Y.-S. Hsu, "Integrating a mobile augmented reality activity to contextualize student learning of a socioscientific issue," British Journal of Educational Technology, vol. 44, no. 3, pp. E95-E99, 2013.

[17] L.Alem and W. T. Huang, "Recent trends of mobile collaborative augmented reality systems", Springer, 2011, http://www.wseas.us/elibrary/conferences/2014/Malaysia/ACACOS/ACACOS29.pdf.

[18] Wikipedia, "Augmented Reality Landscape", $11 \quad$ August 2012, https://en.bywiki.com/wiki/Augmented_reality

[19] E. Sutherland, "A head-mounted three-dimensional display", in Proceedings of the December 9-11, 1968, fall joint computer conference, part I. ACM, 1968, pp. 757-764.

[20] D.W. Roberts, J. W. Strohbehn, J. F. Hatch, W. Murray, and H. Kettenberger, "A frameless stereotaxic integration of computerized tomographic imaging and the operating microscope", Journal of neurosurgery, vol. 65, no. 4, pp. 545-549, 1986.

[21] Azuma, R., Baillot, Y., Behringer, R., \&Feiner, S. (2001). Recent advances in augmented reality. Computer Graphics and Applications. IEEE, 21(6), 3447. 
[22] H.-Y. Chang, H.-K. Wu, and Y.-S. Hsu, "Integrating a mobile augmented reality activity to contextualize student learning of a socioscientific issue", British Journal of Educational Technology, vol. 44, no. 3, pp. E95-E99, 2013.

[23] Billinghurst, M., \&Dunser, A. (2012). Augmented reality in the classroom. Computer, 45(7), 56-63

[24] S.Yuen, G. Yaoyuneyong, and E. Johnson, "Augmented reality: An overview and five directions for ar in education," Journal of Educational Technology Development and Exchange, vol. 4, no. 1, pp. 119-140, 2011.

[25] R. G. Thomas, N. William John, and J. M. Delieu, "Augmented reality for anatomical education," Journal of visual communication in medicine, vol. 33, no. 1, pp. 6-15, 2010.

[26] L. F. Johnson, A. Levine, R. S. Smith, and K. Haywood, "Key emerging technologies for elementary and secondary education.”, Tech Directions, vol. 70, no. 3, pp. 33-34, 2010.

[27] Kiyokawa, K., Billinghurst, M., Hayes, S., Gupta, A., Sannohe, Y., \& Kato, H. (2002). Communication Behaviors of Co-Located Users in Collaborative AR Interfaces. IEEE

[28] Hawkins Mathew, "Augmented Reality Used To Enhance Both Pool And Air Hockey Game Set WatchOctober 15", 2011. https://en.bywiki.com/wiki/Augmented_reality

[29] Wikipedia, "List of augmented reality software", June 2013 https://en.wikipedia.org/wiki/Augmented_reality\#Literature

[30] Abu-Dalbouh, H.,"Developing Mobile Tracking Applications For Patient Treatment". Computer and Information Science - Canadian center of science and education, Vol. 12, Issue 1, pp: 12-24. February 2019. DOI: $10.5539 /$ cis. v12n1p12

[31] Abu-Dalbouh, H.M.,"A Questionnaire Approach Based on the Technology Acceptance Model for Mobile Tracking on Patient Progress Applications". J. Comput. Sci., Vol. 9, Issue 6, pp: 763-770. June 2013. DOI:10.3844/jcssp.2013.763.770. http://thescipub.com/PDF/jcssp.2013.763.770.pdf

[32] Abu-Dalbouh, H., and Almueit, M. Z., "Designing Mobile Tracking Solution in Monitoring Patients". ICIT 2013 The 6th International Conference on Information Technology. May 2013. https://www.semanticscholar.org/author/Hussain-Mohammad-Abu-Dalbouh/2422479

[33] Abu-Dalbouh, H., " m-TOPP-UML: An Extension to UML for the Modeling of Mobile Tracking on Patient Progress System". Research Journal of Applied Sciences, Engineering and Technology, Vol. 7, Issue 7, pp: 1202-1208. February 2014.Available: http://maxwellsci.com/print/rjaset/v7-13881394.pdf

[34] Abu-Dalbouh, H.,"A Proposed mHealth Model for Improving the Quality Care in Hospitals. Research Journal of Applied Sciences", Engineering and Technology, Vol. 7, Issue 7, pp: 1215-1219. February 2014. Available: http://maxwellsci.com/print/rjaset/v7-1401-1405.pdf

[35] Abu-Dalbouh, H., AlJibreen, G., AlDowighri, N.,"Generic Modelling Using Uml Extensions for Queens Challenge Puzzle Game From 1 to 25 Levels System". International Journal of Software Engineering \& Applications (IJSEA), Vol. 9, Issue 6, pp: 31-39. November 2018. Available: http://aircconline.com/ijsea/V9N6/9618ijsea03.pdf

[36] Abu-Dalbouh, H., Al-Matrouk, M., Al-Zwaid, N and Al-Handi., "A Proposal of a Standardized Electronic Health Record for Kingdom of Saudi Arabia". Journal of Computer Science. J. Comput. Sci., Vol. 15, Issue 4, pp: 566-581. June 2019. DOI: 10.3844/jcssp.2019. pp: 566-581, 2019. Available: https://thescipub.com/pdf/10.3844/jcssp.2019.566.581 